\title{
O CASO DO AMIANTO: CONJUNTURA INTERNACIONAL E JURISPRUDÊNCIA DO STF*
}

\author{
Paulo Roberto Blatt** \\ Jânia Maria Lopes Saldanha***
}

\begin{abstract}
RESUMO: O texto descreve os atores, processos, discursos e valores envolvidos no caso do amianto. De um lado, valores econômicos fomentam a globalização de cima. De outro, a defesa da saúde e do meio ambiente promovem a globalização que vem de baixo. O debate acontece nas esferas nacional e internacional. $\mathrm{O}$ assunto, que foi julgado duas vezes pelo STF, está em julgamento outra vez.
\end{abstract}

PALAVRAS-CHAVE: Amianto. Globalização. Saúde. Meio Ambiente. Supremo Tribunal Federal.

ABSTRACT: This paper describes the actors, processes, discourses and values involved in the asbestos case. On the one hand, economic values foment the globalization from above, but on the other hand, the protection of health and environment promotes the globalization from below. The debate comprehends the national and international spheres. The brazilian Supreme Federal Court has judged the question twice, but it is under discussion again.

KEY-WORDS: Asbestos. Globalization. Health. Environment. Supreme Federal Court.

*Resultado parcial da pesquisa intitulada "O Sistema Autônomo de Solução de Controvérsias do Mercosul e as Cortes Supremas de Justiça dos seus Países-membros: Direitos Humanos e perspectivas para a consolidação da cidadania” desenvolvida com apoio do Conselho Nacional de Desenvolvimento Científico e Tecnológico - CNPq - Brasil, sob a Coordenação da Prof ${ }^{a}$. Drª . Jânia Maria Lopes Saldanha.

*Aluno do Curso de Direito da Universidade Federal de Santa Maria. Bolsista PIBIC/CNPq/UFSM

**** Doutora em Direito da UNISINOS. Mestre em Integração Latino-Americana. Coordenadora e Professora do Mestrado em Integração LatinoAmericana da Universidade Federal de Santa Maria. Professora do Curso de Direito da mesma Universidade. Advogada. Orientadora.

\section{CONSIDERAÇÕES INICIAIS}

A tomada de consciência pelo homem da importância vital que representa a proteção ao meio ambiente pode ser considerada recente se comparada com o período em que o mesmo se encontra usando dos recursos naturais. No entanto, vislumbrando-se diariamente as agressões ao meio ambiente, a própria consciência a pouco anunciada é questionável.

Nesse contexto, dois valores essenciais estão em permanente confronto, quais sejam o desenvolvimento econômico e a proteção ao meio ambiente. Cada um deles pode ser inserido respectivamente nos processos de globalização hegemônica e globalização contra-hegemônica. Cada um desses processos se vale de lógicas diferenciadas: no primeiro, lucro e concorrência, enquanto que no segundo prevalece a solidariedade. Nesse contexto, o objetivo do presente artigo é analisar esses processos à luz do caso do amianto.

A primeira parte do trabalho (1) tem a finalidade de identificar quais são os principais atores envolvidos na questão, bem como as posições adotadas em razão os interesses que visam proteger. Uma vez identificados, os mesmos serão alocados dentro dos marcos da globalização hegemônica e contra-hegemônica. 
A segunda parte do trabalho (2) retrata a atuação do Poder Judiciário Brasileiro no contexto das globalizações. Assim, serão discutidos alguns casos submetidos ao Supremo Tribunal Federal (STF), em sede de controle de constitucionalidade concentrado. Ver-se-á que o julgamento do tribunal corrobora a posição política adotada pelo Brasil. Contudo, acontecimentos recentes podem vir a alterar a compreensão do órgão julgador.

\section{O CASO DO AMIANTO: A ARTICULAÇÃO GLOBAL DOS ATORES E DISCURSOS}

O amianto, também conhecido como asbesto, é um termo que designa um grupo de minerais que se agrupam em torno da variedade crisotila ou dos anfibólios, que apresentam alta resistência mecânica, são incombustíveis, possuem baixa condutividade térmica, boa capacidade de isolação térmica e acústica, flexibilidade, afinidade com cimento e resinas e estabilidade em ambientes de pH variável. ${ }^{1}$ No decorrer do texto, a expressão amianto será utilizada para referir o amianto crisotila.

Em vista de tais características, um vasto campo de utilização foi conferido ao referido mineral, destacando-se produtos de cimento amianto (telhas onduladas, placas de revestimento, tubos, caixas d'água), produtos têxteis, isolantes térmicos, produtos de fricção (discos de embreagem, pastilhas e lonas de freio de veículos). ${ }^{2}$ De outro lado, o uso do amianto é combatido em razão de ser prejudicial ao meio ambiente e à saúde, causando principalmente as doenças conhecidas como asbestose (fibrose pulmonar), câncer de pulmão (tumor maligno), mesotelioma (tumor maligno de pleura e pericárdio - hipótese mais rara). ${ }^{3}$

A compreensão da complexa questão em torno do amianto perpassa pelo conhecimento dos atores envolvidos e os respectivos discursos (2.1), bem como o alinhamento dos mesmos à fenômenos que ultrapassam os limites estatais (2.2).

\subsection{Os atores e os discursos acerca do amianto}

No embate a respeito do amianto, uma gama de atores públicos e privados, nacionais e internacionais radica posições diversas (pró-amianto e contra-amianto). Destarte, digladiam-se aqueles que buscam o banimento total do seu uso e aqueles que defendem o uso controlado. O debate transcende o espaço estatal, podendo-se

\footnotetext{
${ }^{1}$ SCLIAR, Claudio. Amianto: mineral mágico ou maldito? Ecologia humana e disputa político-econômica, p. 15-18. 
considerá-lo um tema global, no qual também podem ser fundidas normas nacionais e normas internacionais, em temas de meio ambiente, meio ambiente do trabalho, saúde, comércio, etc. Trata-se, portanto, de um debate plural.

\section{a) Atores pró-amianto e o uso controlado}

Sendo o amianto um mineral, destaca-se primeiramente a atuação dos países (atores públicos) onde se encontram as jazidas em exploração. Segundo o Departamento Nacional de Política Mineral (DNPM) ${ }^{4}$, Rússia (39,7\%), China (17,2\%), Cazaquistão (15\%), Canadá (10,3\%), Brasil (9,7\%) e Zimbábue (4,7\%) detêm 96,6\% da produção mundial de amianto. ${ }^{5}$ Nacionalmente, a indústria do amianto representa importante fonte de renda para o Município de Minaçu e para o Estado de Goiás, onde a Mina Cana Brava é explorada pela SAMA. ${ }^{6}$ Além destes, situam-se deste lado o Instituto Brasileiro da Crisotila (inspirado no Instituto Crisotila do Canadá) e a Confederação Nacional dos Trabalhadores na Indústria. Da mesma forma, posiciona-se a Eternit ${ }^{7}$, cuja produção é voltada para a construção civil.

Estes atores são os responsáveis pela elaboração e difusão da tese do uso controlado, sobre a qual diversas informações foram sintetizadas e divulgadas pelo Instituto Brasileiro da Crisotila. ${ }^{8}$ Sustenta-se, primeiramente que o amianto não é um problema de saúde pública, mas sim ocupacional. O amianto permitido no Brasil é o menos agressivo, bem como as indústrias desenvolveram tecnologia capaz de tornar o processo de extração e industrialização ${ }^{9}$ seguro aos trabalhadores, havendo respeito à legislação e fiscalização pelo poder público.

Na década de 1980 ocorre a adesão explícita do Canadá ao uso controlado. No contexto internacional, em meados da década de 1990, o segmento empresarial ${ }^{10}$ publica um acordo denominado Memorandum de Entendimento - Uma política de uso responsável do amianto-crisotila, cujo objetivo era impedir a venda do minério às empresas que não cumprissem normas de segurança, bem como cooperar com os governos dos países importadores e Organismos Internacionais. ${ }^{11}$

\footnotetext{
${ }^{4}$ O DNPM é uma autarquia vinculada ao Ministério de Minas e Energia.

${ }^{5}$ SACRAMENTO FILHO, Alcebíades Lopes. Boletim Informativo do Amianto 2007, p. 5

${ }^{6}$ SAMA S.A. - Minerações Associadas. Informações disponíveis em <www.sama.com.br> Acesso em 25 set. de 2007.

${ }^{7}$ BRUM, Eliane; CANÇADO, Patrícia; BARROCAL, André. Vida e morte. Época. São Paulo, n. 360, p. 10.

${ }^{8}$ Disponível em <www.crisotilabrasil.org.br> Acesso em 22 set. 2007.

${ }^{9}$ São exemplos disso: a) despoeiramento; b) recorte de telhas em cabines enclausuradas; c) moinhos de cacos nas fábricas; d) treinamento e proteção individual; e) moldagem de pequenas peças feitas a úmido.

${ }^{10}$ JM Asbestos, Icn; LAB Crysotile, Inc; Sociedade Anônima Mineração de Amianto (SAMA); African Associated Mines (PVT), Limited; HVL Asvestos (Swaziland) Limited. Documento na íntegra: In: SCLIAR, op. cit., p. 137-139.

${ }^{11}$ SCLIAR, op. cit., p. 52-53.
} 
Filiando-se, portanto a essa tese, a Lei 9055/95 dispõe sobre a extração, industrialização, utilização, comercialização e transporte do asbesto/amianto e derivados. Proíbe diversos tipos de amianto $^{12}$, permitindo apenas a realização de tais atividades com o amianto crisotila. A justificativa do Brasil em adotar esta tese fica por conta do Boletim Informativo do Amianto, publicado pelo DNPM, que em suas duas edições expôs:

A exportação da produção de amianto crisotila gera divisas da ordem de US\$ 50 milhões por ano. Quaisquer restrições ao uso do amianto crisotila causariam prejuízos elevados à balança comercial brasileira, da ordem de US\$ 180 milhões/ano com a importação de PVA, celulose e microssilica utilizados como substitutos. Além disso o país ficaria refém das variações cambiais da moeda norte-americana e das oscilações do mercado petrolífero. E veria ainda o preço total da construção civil aumentar cerca de $30 \%$ em relação a mesma cobertura contendo amianto crisotila, com uma durabilidade dos produtos reduzida em mais de $60 \% .^{13}$

Do exposto, é perceptível que a economia é o valor protegido pela tese do uso controlado, já que são poucos países responsáveis pelo comércio mundial do produto. Diante de estudos contundentes no sentido da nocividade das fibras de amianto, não é possível sustentar-se que o mesmo não oferece risco algum. Dessa forma, sob o manto do uso controlado, busca-se perpetuar tanto os lucros como as receitas tributárias da atividade, ainda que em detrimento do meio ambiente e da saúde.

\section{b) Atores contra-amianto: banimento e substituição}

Por outro lado, o uso controlado é questionável tanto do ponto de vista do direito à saúde quanto da proteção ao meio ambiente. Deste lado, encontram-se os países que já baniram o amianto ${ }^{14}$ bem como organizações não governamentais, tanto em nível nacional, a exemplo da Associação Brasileira dos Expostos ao Amianto (ABREA) e da Associação Baiana dos Expostos ao Amianto (ABEA), como global representada pela Rede Ban Asbestos (Ban Asbestos Network), cuja coordenação regional fica a cargo da Rede Virtual-Cidadã pelo Banimento do Amianto na América

\footnotetext{
${ }^{12}$ Anfibólios: Actinolita, amosita, antofilita, tremolita.

${ }^{13}$ SACRAMENTO FILHO, op. cit., p. 11.

${ }^{14}$ Lista de Países que baniram o amianto: Alemanha (1993), Arábia Saudita (1998), Argentina (2001), Austrália (2003), Áustria (1990), Bélgica (1998), Burkina Faso (1998), Chile (2001), Chipre (2005), Coréia do Sul (a partir de 2009), Croácia (2006), Dinamarca (1986), Egito (2005), Emirados Árabes (2000), Eslováquia (2005), Eslovênia (1996), Espanha (2002), Estônia (2005), Finlândia (1992), França (1996), Gabão, Grécia (2005), Holanda (1991), Honduras (2004), Hungria (2005), Irlanda (2000), Islândia (1983), Itália (1992), Japão (2004), Jordânia, Kuwait (1995), Látvia (2001), Liechtenstein, Lituânia (2005), Luxemburgo (2002), Malta (2005), Noruega (1984), Nova Caledônia, Nova Zelândia (2002), Polônia (1997), Portugal (2005), Principado de Mônaco (1997), Reino Unido (1999), República Checa (2005), Seychelles, Suécia (1986), Suíça (1989), Uru guai (2002), União Européia (2005). Disponível em <www.abrea.org.br> Acesso em 30 de agosto de 2007.
} 
Latina. ${ }^{15} \mathrm{O}$ apoio da indústria fica por conta da Brasilit, controlada pelo Gupo Francês Saint-Gobain, que após o banimento naquele país em 1996, abandonou a antiga parceira Eternit e passou a investir em materiais substitutivos e brigar pela ampliação desse novo mercado. ${ }^{16} \mathrm{Na}$ defesa dos interesses dos consumidores, encontra-se o IDEC. ${ }^{17}$

Sustenta-se que o problema transcende a esfera ocupacional, sendo uma ameaça à saúde pública e ambiental, pondo em risco os trabalhadores (tanto na extração, como na industrialização), consumidores, moradores em áreas próximas de minas e fábricas e o meio ambiente. No Brasil, que anda na contramão influenciado pelo forte lobby pró amianto - atores privados (empresas relacionadas à extração, industrialização, comercialização de derivados de amianto) e públicos (em especial o Estado de Goiás e o Município de Minaçu), a Associação Brasileira dos Expostos ao Amianto - ABREA, criada em 1995, lidera a luta que, em suma, defende o total banimento do amianto. ${ }^{18}$ Outro fundamento levantado pelos que defendem esta bandeira é a inexistência de limites seguros à exposição. ${ }^{19}$

Após a apresentação dos atores e discursos envolvidos no tema em estudo, fazse necessário compreender como os mesmos se inserem no contexto internacional, mais precisamente nas formas de globalização que podem ser observadas.

\subsection{O amianto no contexto da globalização}

Os atores e discursos analisados na parte anterior articulam-se de forma a reforçar suas posições, visando assim concretizar os valores que defendem. Essa é a razão de que em ambos os casos o debate não se restringe aos limites estatais. Em vista disso, o tema amianto deve ser compreendido também no contexto do processo de globalização.

A história da humanidade conheceu diversos períodos e processos de globalização motivados por fenômenos de ordem religiosa, comercial, política. $^{20}$ Contudo, o termo globalização está relacionado a diferentes conjuntos de relações sociais. Observa-se duas dinâmicas opostas, identificadas como globalização hegemônica e globalização contra-hegemônica, cada uma fomentada por dois modos específicos de se produzir. A primeira estrutura-se a partir dos localismos globalizados

\footnotetext{
${ }_{16}^{15}$ Disponível em <www.abrea.org.br> Acesso em 30 de setembro de 2007.

${ }^{16}$ BRUM, op. cit., p. 10

${ }^{17}$ Informações disponíveis em <www.idec.org.br> Acesso em 06 de setembro de 2007.

${ }^{18}$ CASTRO, Hermano; GIANNASI, Fernanda; NOVELLO, Cyro. A luta pelo banimento do amianto nas Américas: uma questão de saúde pública, p. 908; GIANNASI, Fernanda. A construção de contra-poderes no Brasil na luta contra o amianto: a globalização por baixo, p. 4 .

${ }_{19}$ MENDES, René. Asbesto (amianto) e doença: revisão do conhecimento científico e fundamentação para uma urgente mudança da atual política brasileira sobre a questão, p. 18 .

${ }^{20}$ Cf. OLIVEIRA, Odete Maria de. Teorias globais e suas revoluções: elementos e estruturas.
} 
(fenômeno pelo qual determinada condição local é globalizada com sucesso) e dos globalismos localizados (impacto específico que os localismos globalizados causam no local). A segunda, por sua vez, é erigida sob o cosmopolitismo insurgente e subalterno (resistência transnacional organizada contra a globalização hegemônica - conjunto heterogêneo de iniciativas, movimentos e organizações) e o patrimônio comum da humanidade (lutas transnacionais por valores ou recursos, cujo sentido apenas é compreendido se tratado globalmente). ${ }^{21}$

Especificamente no campo do direito, a globalização hegemônica pode dar-se através do que Mireille Delmas-Marty chama de mercado da lei, processo que ocorre através da exportação de um modelo nacional de regulação. Disso decorre tanto uma adaptação legislativa como jurisprudencial no sentido buscado pelas empresas multinacionais. ${ }^{22}$ Exemplo disso, ligado ao presente tema, é a Convenção 162 da Organização Internacional do Trabalho, que dispõe sobre a utilização do asbesto com segurança, aprovada pela Conferência Internacional do Trabalho em 1986 diante da pressão dos países produtores e exportadores de crisotila, liderados pelo Canadá e

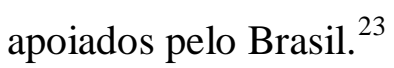

O que se percebe é que as posições em torno do amianto podem ser alinhadas em cada um dos processos de globalização. Os defensores do uso controlado, atendendo precipuamente aos interesses econômicos, filiam-se e unem-se na posição do processo de globalização que vêm de cima. Por outro lado, aqueles que buscam o banimento e conseqüente substituição por materiais alternativos, em prol da saúde e do meio ambiente, constituem-se articuladamente em redes transnacionais fomentando a globalização que vem de baixo. ${ }^{24}$

Sustenta-se dessa forma que a tese do uso controlado constitui-se num localismo globalizado, pois se origina dos países exportadores, especialmente a partir do Canadá. Ao ser exportada, tal posição tem o impacto específico na legislação e posicionamento dos demais países e, assim, cumpre com o papel de globalismo localizado. Do outro lado, as lutas pelo banimento e substituição das fibras de amianto congregam os esforços na forma de redes transnacionais, em exercício do cosmopolitismo insurgente e subalterno, na defesa da saúde e meio ambiente, cuja proteção apenas tem sentido se levada a cabo globalmente, exemplos de patrimônio comum da humanidade.

\footnotetext{
${ }^{21}$ SANTOS, Boaventura de Sousa. A gramática do tempo: para uma nova cultura política, p. 437-441.

${ }^{22}$ DELMAS-MARTY, Mireille. Três desafios para um direito mundial, p. 13-17.

${ }^{23}$ MENDES, op. cit., p. 15.

${ }^{24}$ GIANNASI, Fernanda. A construção de contra-poderes no Brasil na luta contra o amianto: a globalização por baixo, p. 15-21
} 
No entanto, ao que tudo indica, a questionável opção pelo uso controlado foi confirmada pela cúpula do Poder Judiciário, ainda que não expressamente. É disso que trata o próximo capítulo.

\section{O CASO DO AMIANTO NA CÚPULA DO PODER JUDICIÁRIO BRASILEIRO}

Considerando a complexidade que envolve o tema, o desafio proposto é analisar a situação a partir da atuação do Supremo Tribunal Federal, órgão máximo do Poder Judiciário Brasileiro. Por traz da tese do uso controlado, encontram-se argumentos de índole econômica, situação que os coloca no contexto da globalização que vem de cima. Já aqueles que defendem o banimento da fibra, fortalecem e interagem como expoentes da globalização que vem de baixo, visando à proteção do meio ambiente e da saúde.

O Brasil, pelos argumentos já expostos, adotou a posição do uso controlado através da aprovação de legislação federal. Contudo, sendo a matéria de competência legislativa concorrente da União e dos Estados, não tardaram estes em usá-la. A tensão que se instaurou foi a de que União e alguns Estados $^{25}$ tiveram posicionamentos diversos, ou seja, ao contrário da primeira, os segundos optaram pelo banimento.

Quanto ao sistema de divisão de competências, veja-se que elas derivam da opção pela forma federada de Estado. Atendendo ao princípio da predominância do interesse, buscou o legislador constituinte conferir à União as matérias de interesse geral, aos Estados matérias de interesse regional, aos Municípios matérias de interesse local. ${ }^{26}$ Assim, formou-se um complexo sistema que combina competências enumeradas para a União (art. 21 e 22) e para os Municípios (art. 30), e residual para os Estados (art. $25, \S 1^{\circ}$ ), exclusivas ou privativas (delegáveis - art. 22, parágrafo único), áreas de atuação comuns e competências legislativas concorrentes da União e Estados. ${ }^{27}$

Assim, a discussão fica em torno da seguinte situação: podem os Estados filiarem-se ao banimento enquanto a União ao uso controlado? Ou ainda, o cerne da questão discutida reside neste ponto: não tendo a União proibido totalmente o amianto/crisotila, os Estados poderiam fazê-lo ${ }^{28}$ A concepção de federalismo está

\footnotetext{
${ }^{25}$ Mato Grosso do Sul, São Paulo, Rio Grande do Sul, Rio de Janeiro e Pernambuco

${ }^{26}$ SILVA, José Afonso da. Curso de Direito Constitucional Positivo, p. 476.

${ }^{27}$ SILVA, op. cit., p. 477.

${ }^{28}$ LEME MACHADO, Paulo Afonso. Federalismo, amianto e meio ambiente: julgado sobre competência. In: CANOTILHO, José Joaquim Gomes; LEITE, José Rubens Morato. Direito constitucional ambiental brasileiro, p. 228.
} 
como pano de fundo de uma disputa entre privilegiar o desenvolvimento econômico ou a saúde pública e o meio ambiente.

Para cumprir tal escopo, serão analisadas algumas Ações Diretas de Inconstitucionalidade, duas já julgadas (3.1) e uma com o julgamento liminar suspenso (3.2). Diversas questões foram debatidas em cada processo, porém o fio condutor das decisões é o mesmo, razão pela qual receberá tratamento individualizado neste ensaio. Considerando que o STF se atrelou à questão formal da divisão de competências legislativas, perceber-se-á que pouca coisa disse a respeito do amianto.

\subsection{A globalização que vem de cima beneficiada pelo formalismo}

Nesta parte do trabalho, o desafio é demonstrar como persiste na cúpula do Poder Judiciário uma visão formalista que ofusca valores substanciais contidos na Constituição Federal. Ainda quando em cena temas relevantes, como é o caso do amianto crisotila, o Pretório Excelso se apega às regras de competência e deixa de lado qualquer análise fundada em outros valores.

O caso do amianto chegou ao Supremo Tribunal Federal em sede de controle concentrado de constitucionalidade motivado pela aprovação de leis estaduais que baniram o amianto dos respectivos territórios. Nesta ocasião, serão objeto de análise parcial as decisões da ADI 2396 e da ADI 2656, ajuizadas pelo Governador do Estado de Goiás contra, respectivamente, a Lei 2.210/01 do Estado do Mato Grosso do Sul e Lei 10.813/01 do Estado de São Paulo.

De fato, a respeito do amianto, a única coisa que o STF disse é que:

Não cabe a esta Corte dar a última palavra a respeito das propriedades técnicocientíficas do elemento em questão e dos riscos de sua utilização para a saúde da população. Os estudos nesta seara prosseguem e as conclusões deverão nortear as ações das autoridades sanitárias. Competência do Supremo Tribunal Federal circunscrita à verificação de contraste inadmissível entre a lei em exame e o parâmetro constitucional. ${ }^{29}$

Se por um lado é certo que não se exige que o STF manifeste-se sobre conhecimento técnico e científico, é inarredável que tal afirmação atrairia a aplicação do Princípio da Precaução. Todavia não foi isso o que aconteceu.

Em ambas as ações, entendeu o Pretório que houve invasão da competência legislativa concorrente da União e dos Estados sobre produção e consumo (CF, art. 24, 
IV), proteção ao meio ambiente e controle da poluição (CF, art. 24, VI), proteção e defesa da saúde (CF, art. 24, XII). Para o STF a competência legislativa concorrente do Estado abre-se quando: a) toda vez que não haja legislação federal, quando então, mesmo sobre princípios gerais, poderá a legislação estadual dispor; b) quando, existente legislação federal que fixe os princípios gerais, caiba complementação ou suplementação para o preenchimento de lacunas, para aquilo que não corresponda à generalidade; ou ainda, para a definição de peculiaridades regionais. No caso, existia legislação federal (Lei 9055/95) fixando os princípios gerais (proíbe os anfibólios e produtos que os incorporem; proíbe a pulverização de qualquer tipo de amianto; proíbe a venda a granel das fibras; permite, nos seus termos, a extração, industrialização, utilização e comercialização da crisotila). Nesse caminho, entendeu que as legislações estaduais extrapolaram a sua competência, pois dispuseram em sentido contrário à legislação federal. Assim, foi reconhecido vício de inconstitucionalidade formal, por invasão de competência legislativa da União para legislar sobre normas gerais quanto à produção e consumo, proteção ao meio ambiente e controle da poluição, proteção e defesa da saúde, bem como excesso dos limites da sua competência suplementar. ${ }^{30}$

Ainda que em controle de constitucionalidade concentrado o STF não analise questão de fato, ou no caso, a nocividade ou não do amianto crisotila, nada impedia ao tribunal analisar outros aspectos, relacionados com o direito à saúde e ao meio ambiente. Nessa mesma linha de raciocínio, insere-se o princípio da precaução.

Por certo, o princípio da precaução não vem expressamente previsto na Constituição Federal, mas emana de diversos dispositivos da mesma, a exemplo do art. $225, \S 1^{\text {o }}$, II, II , IV e V. ${ }^{31}$ Conforme o referido princípio, havendo perigo de dano grave ou irreversível, a ausência de certeza científica não é fundamento para adiar medidas com o fim de evitar a consumação da degradação ambiental. ${ }^{32}$

Cabe indagar se era possível ao STF analisar a constitucionalidade das leis sobre outros valores, esses substanciais, tal como o princípio da precaução. Essa observação é importante, já que o STF manifestou que não lhe cabia decidir sobre as propriedades técnicas e científicas do amianto, porém reconheceu que inexiste "certeza científica" sobre as mesmas. Assim, não havendo certeza da nocividade ou não da crisotila, bem como diante dos prejuízos já consumados e daqueles que ocorrerão, com base no princípio da precaução, o uso do amianto deveria ser restringido até a existência

\footnotetext{
${ }^{30}$ ADI 2396 e ADI 2656.

${ }^{31}$ LEITE, José Rubens Morato. Sociedade de Risco e Estado. In: CANOTILHO, José Joaquim Gomes; LEITE, José Rubens Morato. Direito constitucional ambiental brasileiro, p. 178.

${ }^{32}$ LEITE, op. cit., p. 175.
} 
da "certeza científica" - ou no mínimo um consenso estabelecido no meio científico. Sendo o princípio da precaução um princípio do Direito Ambiental Brasileiro, o mesmo deve nortear as ações administrativas, legislativas e judiciais.

Por outro lado, os fundamentos de índole econômica não apenas fizeram-se presentes em vários pontos das decisões, como os mesmos foram acolhidos de forma expressa para justificar o interesse de agir, da pertinência temática bem como a concessão da medida liminar (ADI 2396) e do imediato encaminhamento ao plenário para julgamento (ADI 2656).

Dessas afirmações, depreende-se que o STF, ainda que de forma implícita, optou por assegurar os interesses econômicos públicos e privados, já que a mina Cana Brava é explorada em regime de concessão por uma empresa privada que investiu muito na atividade, bem como esta rende divisas para o Município de Minaçu e para o Estado de Goiás. Logo, o STF endossou a posição brasileira, aderindo uso controlado, deixando de fortalecer a globalização que vem de baixo.

Essas conclusões encontram eco na doutrina:

Conquanto os argumentos decisivos para declarar a inconstitucionalidade das restrições e proibições fixadas pelo Estado do Mato Grosso do Sul, não é possível afirmar que o caso foi decidido exclusivamente a partir de um problema objetivo de normas de organização e procedimento. Em primeiro lugar, porque é visível que escolhas foram realizadas pelo tribunal, ainda que não se tenha declarado que (mesmo que expressas e utilizadas para outra finalidade) foram decisivas para o julgamento da ação. Segundo, porque, na hipótese de eventual preterição dos argumentos econômicos, provavelmente não se teria verificado, no caso, a concessão de uma medida liminar no provimento cautelar pleiteado, razão pela qual, pelo menos a princípio, não parece ser possível sustentar restrições ou razões para que problemas materiais sejam preteridos em favor de problemas procedimentais. ${ }^{33}$

\subsection{A globalização que vem de baixo: novos rumos para o caso do amianto?}

Os acontecimentos recentes no cenário nacional referente ao caso do amianto deixam o debate mais acalorado. Para tanto, mister a incursão na ADI 3937 ajuizada pela Confederação Nacional dos Trabalhadores na Indústria - CNTI, contra a Lei 12.684/07 do Estado de São Paulo. O diploma estadual impugnado não se diferencia muito dos casos anteriores, já que a finalidade é a mesma: o banimento do amianto no âmbito do Estado de São Paulo, pela segunda vez. Por sua vez, o pedido de

\footnotetext{
${ }^{33}$ AYALA, Patryck de Araújo. O novo paradigma constitucional e a jurisprudência ambiental do Brasil. In: CANOTILHO, José Joaquim Gomes; LEITE, José Rubens Morato. Direito constitucional ambiental brasileiro, p. 368.
} 
inconstitucionalidade tem os mesmos fundamentos - tanto que se fundamenta nos julgamentos anteriores. A novidade fica por conta da atuação de novos atores, já que foi ajuizada pela CNTI, bem como recentemente foi deferida a participação da ABREA como amicus curiae. Isso chama a atenção, já que anteriormente eram apenas atores públicos envolvidos. Resta, portanto, saber se haverá mudança no entendimento do STF. Esse é o tema do presente capítulo.

Segundo informações obtidas no site do Supremo Tribunal Federal ${ }^{34}$, atualmente o julgamento encontra-se suspenso em razão do pedido de vistas feito pelo Min. Joaquim Barbosa. Até o momento, já foram proferidos os votos favoráveis ao deferimento da medida cautelar por parte do Min. Marco Aurélio, Min. Carmem Lúcia e Min. Ricardo Lewandowski. Porém, o Min. Eros Grau, votando pelo não deferimento da medida cautelar, instaurou a divergência quanto à matéria em votação.

Enriquecendo o debate já não unânime, a ABREA submeteu suas considerações que já foram recebidas pelo tribunal. ${ }^{35} \mathrm{O}$ primeiro aspecto suscitado é a alteração do contexto histórico, econômico e social, não servindo, portanto, os julgados anteriores como parâmetros para o julgamento em questão.

Considerando o princípio da implementação progressiva dos direitos humanos, a interpretação das regras de competência deve ser ampla, considerando a lei federal como o piso de proteção. Assim, os Estados de forma suplementar estariam autorizados a ampliar a proteção. Em decorrência disso, a revogação da lei impugnada representaria retrocesso social, já que a mesma apenas estaria impedida de legislar de forma menos protetiva que a norma federal.

Igualmente, sustentou o amicus curiae que o STF deve conferir uma interpretação conforme à normativa federal, fixando o seu sentido e o seu limite como marco protetivo inicial, para que em cotejo com a normativa estadual, ambas sejam compatíveis e ampliem a proteção ao meio ambiente e saúde. Entendimento contrário suscitaria a inconstitucionalidade formal e material da Lei 9055/95: a) inconstitucionalidade formal: em vista de extrapolar o limite da generalidade da norma federal imposto pela Constituição Federal; b) inconstitucionalidade material: na medida em que autoriza a extração, industrialização, utilização e comercialização de substancia comprovadamente cancerígena, violando os princípios constitucionais de proteção à saúde e meio ambiente.

\footnotetext{
${ }^{34}$ Disponível em <www.stf.gov.br> Acesso em 26 de setembro de 2007.

${ }^{35}$ Arquivo disponibilizado via e-mail pelos procuradores da ABREA.
} 
Em vista disso, ressoa na doutrina o entendimento favorável a maior participação dos Estados no federalismo:

Suplementar não é desunir. Suplementar não é somente ornamentar uma norma geral, como se essa competência representasse uma superfluidade. Adicionar, completar e aprimorar a norma geral federal faz parte de um federalismo participativo e cooperativo. O contrário é praticar um federalismo "consentido", em que as autonomias estaduais não são desejadas, mas somente toleradas. ${ }^{36}$

Com esses argumentos, o que se pretende é verificar as duas possibilidades de interpretação da questão submetida ao STF. Por um lado é possível continuar adotandose uma concepção restritiva das regras de competência legislativa concorrente, como de fato já o fez o tribunal. Assim, sequer é necessário buscar outros fundamentos, pois a questão formal não foi respeitada. Deste modo, o raciocínio é que se a lei federal restringiu, mas não proibiu; logo, permitiu e, se a lei estadual proibir, o Estado legislou contrariamente a lei federal afrontando a competência suplementar de que dispunha. Por outro, a própria concepção da competência legislativa concorrente pode ser mais dinâmica, se o valor da proteção à saúde e ao meio ambiente estiver em primeiro lugar. Assim, o caso poderia ser entendido da seguinte forma: a lei federal restringiu (piso de proteção) e a lei estadual terminou por vedar a utilização do referido produto (teto de proteção), logo no mesmo sentido de proteger o meio ambiente através da aplicação do princípio da precaução, bem como protegendo a saúde pública.

Assim, o exercício da competência legislativa em matéria ambiental deverá sempre privilegiar a maior e mais efetiva preservação do meio ambiente ${ }^{37}$, o que legitima a tese de que a posição em favor do banimento representa um teto de proteção e o uso controlado um piso de proteção.

\section{CONSIDERAÇÕES FINAIS}

A discussão apresentada não teve a finalidade de exaurir a questão em torno do amianto crisotila, mas lançar um olhar sobre as duas posições existentes com relação ao tema, bem como identificar os principais atores. Através da prática dos mesmos, bem como dos seus discursos (uso controlado ou banimento) percebeu-se a conexão com os valores da economia ou da proteção da saúde e meio ambiente. Enfim, as teses foram

\footnotetext{
${ }^{36}$ LEME MACHADO, op. cit., p. 229.

${ }^{37}$ FIORILLO, Celso Antonio Pacheco. Curso de Direito Ambiental Brasileiro, p. 78
} 
caracterizadas e inseridas no contexto da globalização, seja hegemônica ou contrahegemônica.

No cenário nacional, evidencia-se que a posição do uso controlado foi endossada pelo Supremo Tribunal Federal. Além da crítica realizada a partir da tese do banimento, a corte optou por um julgamento sob questões formais (competência), bem como uma concepção minimalista de federalismo. Por outro lado, ao acolher fundamentos de índole econômica em alguns pontos das decisões, evidencia-se que tais valores receberam um tratamento privilegiado, impulsionando a globalização que vem de cima em detrimento da globalização que vem de baixo.

Contudo, o que parecia pacífico já não o é. Assim, a divergência que começa a surgir no julgamento de outra ação, também analisada nos limites do que interessou ao trabalho, pode ensejar uma alteração nesse panorama. Não sendo possível antecipar-se o resultado da mesma, aguarda-se a decisão do STF.

Por fim, muito mais do que filiar-se a uma ou outra posição, o texto cumpriu com o objetivo de analisá-las e retratar sua repercussão no cenário nacional e internacional.

\section{REFERÊNCIAS BIBLIOGRÁFICAS}

BRASIL. Supremo Tribunal Federal. Ação Direta de Inconstitucionalidade n. 2396. Governador do Estado de Goiás e Governador do Estado do Mato Grosso do Sul e Assembléia Legislativa do Estado do Mato Grosso do Sul. Relator: Min. Ellen Gracie. 08 de maio de 2003. Disponível em <www.stf.gov.br> Acesso em: 01 ago. 2007.

BRASIL. Supremo Tribunal Federal. Ação Direta de Inconstitucionalidade n. 2656. Governador do Estado de Goiás e Governador do Estado de São Paulo e Assembléia Legislativa do Estado de São Paulo. Relator: Min. Maurício Corrêa. 08 de maio de 2003. Disponível em <www.stf.gov.br> Acesso em 01 ago. 2007.

BRASIL. Supremo Tribunal Federal. Ação Direta de Inconstitucionalidade n. 3937. Confederação Nacional dos Trabalhadores na Indústria e Governador do Estado de São Paulo e Assembléia Legislativa do Estado de São Paulo. Relator: Min. Marco Aurélio. Disponível em <www.stf.gov.br> Acesso em 01 ago. 2007.

BRUM, Eliane; CANÇADO, Patrícia; BARROCAL, André. Vida e morte. Época. Rio de Janeiro, n. 360, p. 10-13, abril. 2005. Disponível em <www.abrea.org.br> Acesso em 01 set. 2007.

CANOTILHO, José Joaquim Gomes; LEITE, José Rubens Morato. Direito constitucional ambiental brasileiro. São Paulo: Saraiva, 2007.

CASTRO, Hermano; GIANNASI, Fernanda; NOVELLO, Cyro. A luta pelo banimento do amianto nas Américas: uma questão de saúde pública. Ciênc. saúde coletiva, Rio de Janeiro, v. 8, n. 4, 2003. Disponível em: <http://www.scielo.br/scielo.php?

script=sci_arttext\&pid=S1413-81232003000400013\&lng=pt\&nrm=iso $>$. Acesso em: 22 set. 2007. 
DELMAS-MARTY, Mireille. Três desafios para um Direito Mundial. Rio de Janeiro: Lumen Júris, 2003.

FIORILLO, Celso Antonio Pacheco. Curso de Direito Ambiental Brasileiro. 6.ed. São Paulo: Saraiva, 2005.

GIANNASI, Fernanda. A construção de contra-poderes no Brasil na luta contra o amianto: a globalização por baixo. Disponível em <www.abrea.org.br> Acesso em 01 ago. 2007.

MENDES, René. Amianto e política de saúde pública no Brasil. Cad. Saúde Pública, Rio de Janeiro, v. 23, n. 7, 2007. Disponível em:

$<$ http://www.scielo.br/scielo.php?script=sci_arttext\&pid=S0102-

311X2007000700001\&lng=en\&nrm=iso>. Acesso em: 01 oct. 2007.

MENDES, René. Asbesto (amianto) e doença: revisão do conhecimento científico e fundamentação para uma urgente mudança da atual política brasileira sobre a questão. Cad. Saúde Pública, Rio de Janeiro, v. 17, n. 1,2001 . Disponível em: $<$ http://www.scielo.br/scielo.php?script=sci_arttext\&pid=S0102-

311X2001000100002\&lng=pt\&nrm=iso>. Acesso em: 22 set. 2007.

OLIVEIRA, Odete Maria de. Teorias globais e suas revoluções: elementos e estruturas. Ijuí: Ed. Unijuí, 2004.

SACRAMENTO FILHO, Alcebíades Lopes. Boletim Informativo do Amianto 2006. Disponível em <www.dnpm.gov.br> Acesso em: 22 set. 2007.

SACRAMENTO FILHO, Alcebíades Lopes. Boletim Informativo do Amianto 2007. Disponível em <www.dnpm.gov.br> Acesso em: 22 set. 2007.

SANTOS, Bovantura de Sousa. A gramática do tempo: para uma nova cultura política. São Paulo: Cortez, 2006.

SCLIAR, Claudio. Amianto: mineral mágico ou maldito? Ecologia humana e disputa político-econômica.

Belo

Horizonte:

CDI, 1998. 
